Dipublikasikan BUGUH

Badan Pelaksana Kuliah Kerja Nyata

Universitas Lampung

Sekretariat Badan Pelaksana Kuliah Kerja Nyata, Universitas Lampung. Jl. Prof. Dr. Soemantri Brojonegoro No. 1, Bandar Lampung 35145.

\title{
PEMBERDAYAAN MASYARAKAT MELALUI PROGRAM BUNTAH (SABUN MINYAK JELANTAH)
}

\author{
Tarkono $^{1}$, Alferidho Arif ${ }^{2}$, Izzatul Jannah ${ }^{2}$, Muhammad Aldi Ivansyah², Muhammad Reza \\ Pahlevie $^{2}$, Nur Syafira Wasi², Tria Fadilla², Vina Anggraini Safitri ${ }^{2}$ \\ ${ }^{1}$ Jurusan Teknik Elektro/FT, Universitas Lampung \\ ${ }^{2}$ Mahasiswa KKN Periode 12021 Universitas Lampung
}

Penulis Korespodensi:triafadilla11@gmail.com

\begin{abstract}
Abstrak
Limbah minyak goreng (minyak jelantah) yang berasal dari sector rumah tangga maupun kegiatan industri makanan dapat memberikan dampak negatif bagi lingkungan dan kelangsungan hidup manusia jika tidak ditangani dengan baik. Salah satu cara yang dapat dilakukan yaitu dengan mengadakan kegiatan pemberdayaan masyarakat untuk mengelola limbah minyak jelantah menjadi barang yang memiliki nilai jual, misalnya sabun. Proses pembuatan sabun meliputi persiapan alat dan bahan, melakukan penjernihan minyak jelantah, pencampuran semua bahan, pencetakan dan pengemasan. Pelaksanaan kegiatan pemberdayaan masyarakat terkait dengan pengelolaan minyak jelantah menjadi sabun melalui beberapa tahapan kegiatan. Dimulai dengan melakukan sosialisasi, penyuluhan, praktek pembuatan sabun dan evaluasi serta pendampingan. Program pemberdayaan masyarakat ini dapat mendukung terciptanya lingkungan yang produktif, ekonomi mandiri dan juga kreatifitas masyarakat. Produk sabun yang dihasilkan memiliki beberapa keunggulan dari produk sabun pada umumnya yakni, ramah lingkungan karena menggunakan bahan-bahan alami sebagai komposisi pelengkap. Memiliki nilai estetika dalam hal bentuk, warna, dan aroma. Kemudian, sabun ini pula merupakan suistainable product yang minim resiko pemakaian.
\end{abstract}

Kata kunci : minyak goreng bekas, sabun, pemberdayaan masyarakat.

\begin{abstract}
Cooking oil waste (used cooking oil) originating from the household sector and food industry activities can have a negative impact on the environment and human survival if not handled properly. One of the ways that can be done is by holding community empowerment activities to manage used cooking oil waste into goods that have a selling value, for example soap. The process of making soap includes preparing tools and materials, purifying used cooking oil, mixing all ingredients, printing and packaging. The implementation of community empowerment activities related to the management of used cooking oil into soap through several stages of activity. Starting with socialization, counseling, soap making practice and evaluation and assistance. This community empowerment program can support the creation of a productive environment, an independent economy and community creativity. The resulting soap products have several advantages over soap products in general, namely, they are environmentally friendly because they use natural ingredients as a complementary composition. Has aesthetic value in terms of shape, color and aroma. Then, this soap is also a sustainable product that has minimal risk of use.
\end{abstract}

Keywords: used cooking oil, soap, community empowerment 


\section{Jurnal Pengabdian Kepada Masyarakat BUGUH}

Dipublikasikan

Badan Pelaksana Kuliah Kerja Nyata

Universitas Lampung

Sekretariat Badan Pelaksana Kuliah Kerja Nyata, Universitas Lampung.

Ji. Prof. Dr. Scemantri Brojonegoro No. 1, Bandar Lampung 35145.

\section{Pendahuluan}

Desa Gumukmas merupakan salah satu desa yang berada di Kecamatan Pagelaran, Kabupaten Pringsewu. Tepatnya wilayah ini berada di bagian timur dengan jarak sekitar 2,8 km dari Pagelaran sebagai ibukota kecamatan. Masyarakat yang bermukim di desa ini banyak yang berprofesi sebagai pedagang gorengan dan keripik. Hal tersebut mengakibatkan produksi minyak goreng yang telah digunakan atau dikenal sebagai minyak jelantah (waste cooking oil) terbilang cukup banyak.

Jika ditelisik lebih dalam, sebagian besar sektor rumah tangga dan kegiatan usaha lainnya di Desa Gumukmas kerap kali membuang sisa minyak jelantah ke saluran air meskipun dalam jumlah kecil. Pembuangan limbah minyak goreng bekas secara intensif dapat menimbulkan dampak negatif bagi lingkungan dan kelangsungan hidup manusia. Tindakan tersebut disebabkan oleh rendahnya wawasan masyarakat setempat terkait dengan proses pengolahan lebih lanjut dari limbah minyak goreng tersebut. Akibatnya, masih banyak masyarakat umum atau pedagang kuliner yang membuang limbah minyak goreng sembarangan.

Minyak jelantah dapat diolah kembali melalui sistem pemurnian yang selanjutnya dapat diolah menjadi bahan baku industri non pangan, seperti sabun (Naomi et al., 2013). Hal ini disebabkan oleh kandungannya telah mengalami kerusakan sehingga tidak baik untuk dikonsumsi. Sehingga, minyak jelantah hasil filterisasi tersebut tidak untuk dikonsumsi melainkan dapat dibuat sebuah inovasi baru berupa sabun cuci tangan dan sabun hias dalam kemasan souvenir. Sabun dapat dibuat berdasarkan proses saponifikasi, yaitu hidrolisis lemak menjadi asam lemak dan gliserol dalam kondisi basa (Suryandari, 2014).

Berdasarkan hal tersebut, sebagai upaya untuk mengatasi masalah kuantitas limbah minyak goreng yang tinggi, dilakukan kegiatan pemberdayaan masyarakat yang bertujuan untuk meningkatkan nilai tambah bagi limbah minyak goreng dengan mengolahnya menjadi sabun hias. Pelatihan keterampilan mengenai pengolahan limbah minyak goreng menjadi sabun ramah lingkungan sangat bermanfaat bagi masyarakat Indonesia, khususnya masyarakat di Desa Gumukmas yang banyak berprofesi sebagai pengusaha kuliner. Agar usaha kuliner lebih produktif, maka hasil ini dapat digunakan sebagai pembaharuan dalam rangka menghemat pengeluaran dari segi bahan pencuci dan bentuk ekonomi yang mandiri dan kreatif. Bentuk pelatihan tersebut akan dilakukan dengan program pembuatan BUNTAH (Sabun Minyak Jelantah)

Program ini diharapkan memunculkan kesadaran dan peran aktif masyarakat sasaran dalam pelaksanaan pengolahan limbah karena pelestarian lingkungan adalah kewajiban seluruh masyarakat. Melalui program pembinaan kepada masyarakat Desa Gumukmas, Kecamatan Pagelaran, Kabupaten Pringsewu, diharapkan program ini dapat dimanfaatkan secara optimal oeh masyarakat sebagai pengendalian pencemaran lingkungan serta dapat meningkatkan pengetahuan dan keterampilan. Dengan adanya program ini dapat tercipta lingkungan yang produktif dan ekonomi yang mandiri serta kreatif dalam indikator pencapaiannya.

\section{Bahan dan Metode}

Metode yang digunakan dalam kegiatan ini adalah memberikan materi dan praktik/demonstrasi. Peserta menyimak paparan dari pemateri yang dilanjutkan dengan demonstrasi pembuatan sabun minyak jelantah. Kegiatan pertama yang kami lakukan adalah penyamaan persepsi kepada masyarakat dengan melakukan lokakarya yaitu mensosialisasikan program-program yang telah disusun agar semua pihak terutama kelompok wanita tani sebagai mitra dapat secara optimal berperan aktif. Kegiatan ini diawali dengan proses identifikasi area sasaran yaitu desa Gumukmas, kemudian dilanjutkan dengan observasi dan wawancara langsung dengan warga. Jadwal pelaksanaan program pelatihan pembuatan sabun minyak jelantah dilakukan dengan mitra kelompok tani. Ada pun implementasi program yang kami tawarkan adalah sebagai berikut.

1. Sosialisasi program sabun minyak jelantah. 


\section{Jurnal Pengabdian Kepada Masyarakat BUGUH}

Dipublikasikan

Badan Pelaksana Kuliah Kerja Nyata

Universitas Lampung

Sekretariat Badan Pelaksana Kuliah Kerja Nyata, Universitas Lampung.

Ji. Prof. Dr. Soemantri Brojonegoro No. 1, Bandar Lampung 35145 .

2. Penyuluhan pembuatan sabun minyak jelantah. Bentuk kegiatannya adalah berdiskusi terkait latar belakang masalah lingkungan yaitu limbah rumah tangga yaitu minyak jelantah, upaya yang dilakukan mengatasi limbah rumah tangga, faktor-faktor yang mempengaruhi pembuatan sabun minyak jelantah, langkah-langah pembuatan sabun, kegiatan yang harus dilakukan selama proses pembuatan, pengemasan sabun dan cara memasarkan produk sabun minyak jelantah.

3. Praktek pembuatan sabun minyak jelantah dan bahan-bahan tambahan.

4. Evaluasi dan pendampingan.

Kemudian pembagian program dibagi menjadi dua tahap yaitu pengorganisasian mencakup pengadaan alat, bahan, tempat dan kelengkapan lainnya. Kegiatan ini meliputi persiapan alat dan bahan yang digunakan selama proses pengolahan limbah minyak jelantah tersebut serta tempat yang akan dijadikan. Kemudian tahap pelaksanaan program terdiri dari:

- Penjernihan limbah minyak jelantah. Tahapan ini akan melatih masyarakat untuk melakukan proses filtrasi menggunakan kulit pisang sebagai absorbennya. Proses penjernihan ini dilakukan selama 3 hari dengan perbandingan 10 gram kulit pisang untuk $300 \mathrm{Ml}$ minyak jelantah yang telah dipanaskan dalam suhu 100 derajat celcius selama 15 menit (Nasir dkk, 2014)

- Setelah tahapan penjernihan telah dilakukan, tahapan selanjutnya adalah pembuatan sabun sebagai yakni mencampurkan $\mathrm{NaOH} 30$ gram dengan air pada gelas beker sebanyak $105 \mathrm{ml}$ sedikit demi sedikit sembari di aduk perlahan. Setelah $\mathrm{NaOH}$ larut dalam air hingga jernih turunkan suhu hingga $\pm 29^{\circ}$. Kemudian tambahkan pewarna makanan secukupnya, lalu tambahkan $100 \mathrm{ml}$ minyak jelantah murni yang akan digunakan dengan teko bervolume, selanjutnya ditambahkan pengharum pada minyak secukupnya, kemudian campuran selanjutnya diaduk selama 7-10 menit. Setelah tercampur, masukan cairan sabun ke dalam cetakan dan tunggu \pm 3-4 jam hingga sabun menjadi padat. Sabun yang sudah jadi dapat dikemas dengan menarik untuk menjadi sabun hias.

- Setelah selesai dengan pembuatan sabun hias, selanjutnya adalah proses pengemasan dan pembuatan logo produk yang bekerjasama dengan Kelompok Wanita Tani Sekar Tanjung kemudian melakukan kegiatan pemasaran langsung di Pasar Tani Pringsewu selama satu hari.

\section{Hasil dan Pembahasan}

Perlu adanya terobosan baru untuk mengatasi permasalahan limbah minyak jelantah agar dapat menjadi produk yang ekonomis dan bermafaat bagi lingkungan. Hal ini juga mendukung tujuan Pembangunan Berkelanjutan atau Sustainable Development Goals 2030 pada poin ke 12 terkait responsible consumption and production (konsumsi dan produksi yang bertanggung jawab). Solusi progam pembuatan BUNTAH (Sabun Minyak Jelantah) dengan melakukan recycle limbah minyak jelantah yang dijadikan sebagai sabun padat dengan integrasi pewangi alami dan kemasan eco friendly diharapkan secara bertahap dapat membantu Indonesia dalam mewujudkan SDGs 2030.

Sebagaimana yang diketahui, sisa dari produksi yang menggunakan minyak goreng belum terolah secara maksimal yang dapat mengakibatkan berbagai dampak pada lingkungan hidup. Limbah minyak jelantah dari pengolahan rumah tangga tersebut, apabila dibuang ke lingkungan akan sangat berdampak, seperti menurunnya konsentrasi okseigen terlarut didalam air, menjadikan pencahayaan matahari kurang maksimal sehingga organisme di dalam air kekurangan cahaya, pada suhu rendah limbah minyak jelantah akan 11 membeku sehingga menyumbat saluran pipa, dan membuat saluran air pembuangan terganggu (Travis et al, 2008).

Minyak jelantah dapat diolah kembali (recycle) dan dimanfaatkan menjadi produk bernilai ekonomis. Dalam rangka mencapai tujuan konsumsi dan produksi yang bertanggung jawab pada tahun 2030 mendatang, pada dokumen RAN ditetapkan 11 target yang diukur melalui 19 indikator. Target-target tersebut terdiri dari pencapaian pelaksanaan 10 tahun kerangka kerja konsumsi dan produksi yang bertanggung jawab, pengelolaan bahan kimia dan limbah B3, serta pencapaian praktek usaha berkelanjutan. Upaya-upaya yang dilakukan untuk mencapai target-target tersebut dijabarkan pada 


\section{Jurnal Pengabdian Kepada Masyarakat BUGUH}

Dipublikasikan

Badan Pelaksana Kuliah Kerja Nyata

Universitas Lampung

Sekretariat Badan Pelaksana Kuliah Kerja Nyata, Universitas Lampung.

Ji. Prof. Dr. Scemantri Brojonegoro No. 1, Bandar Lampung 35145.

kebijakan, program dan kegiatan yang akan dilakukan oleh pemerintah maupun nonpemerintah. Adanya pengolahan limbah minyak jelantah menjadi sabun padat dengan integrasi pewangi alami dan kemasan ramah lingkungan ini, akan menjadikan solusi baru yang turut mendukung mewujudkan responsible consumption and production di Indonesia. Minyak goreng bekas dapat diolah menjadi sabun mandi baik dalam bentuk padat maupun cair (Wijana dkk., 2010;.Priani, 2010).

Pemanfaatan sabun dihasilkan dari proses hidrolisis minyak atau lemak menjadi asam lemak bebas dan gliserol yang dilanjutkan dengan proses saponifikasi menggunakan basa ( $\mathrm{KOH}$ atau $\mathrm{NaOH})$. Asam lemak bebas yang berikatan dengan basa ini dinamakan sabun (Ketaren, 1986). Pada pembuatan sabun ini dibutuhkan bahan bahan seperti: $100 \mathrm{ml}$ minyak jelantah murni, $\mathrm{NaOH} 30$ gram dengan air pada gelas beker sebanyak $105 \mathrm{ml}$, arang secukupnya, pengharum, dan perwarna makanan alami. Kemudian alat yang digunakan yaitu: pengaduk kayu, spatula, gelas takar, timbangan, wadah tahan panas, cetakan, lap, koran bekas, masker, dan sarung tangan.

Proses pembuatan sabun ini yaitu dengan cara sebagai berikut. Menyiapkan alat dan bahan yang digunakan dengan menghindari peralatan berbahan logam. Lalu, timbang semua bahan yang diperlukan dengan komposisi yang tepat agar. Masukkan soda api ke air pewangi alami. Setelah itu, aduk perlahan campuran antara soda api dan air tersebut hingga terlarut sempurna, setalah itu masukan perlahan minyak jelantah yang telah direndam bersama arang selama dua hari. Perendaman bertujuan untuk menyerap kotoran dan bau dari minyak jelantah. Aduk sampai mencapai kekentalan seperti gel selama kurang lebih 20 menit lalu masukan pewarna makanan serta aduk kembali selama 5 menit. Setelah itu, tuang ke adonan ke dalam cetakan yang ingin digunakan. Diamkan selama satu hari. Lalu, letakan di tempat yang berventilasi bagus. Setelah 3- 4 minggu, sabun bisa digunakan.

Produk ini mempunyai beberapa keunggulan dari produk sabun pada umumnya yakni, ramah lingkungan karena menggunakan bahan-bahan alami sebagai komposisi pelengkap. Memiliki nilai estetika dalam hal bentuk, warna, dan aroma. Kemudian, sabun ini pula merupakan suistainable product yang minim resiko pemakaian. Sabun ini pula memiliki warna dan aroma alami yang beragam dan menyegarkan. Produk didukung oleh kemasan kardus yang menarik dan ramah lingkungan. Selanjutnya, sabun ini dapat sebagai sabun yang multifungsi yang dapat dipakai pada beberapa kegiatan rumah tangga. Dalam proses produksi, bentuk, aroma, dan warna dapat disesuaikan dengan permintaan konsumen oleh karena itu pula, sangat strategis untuk dipasarkan. Saat dipakai, sabun ini mengelurkan sedikit busa sehingga secara langsung dapat menghemat penggunaan air.

Sabun padat minyak jelantah atau dikenal pula sebagai BUNTAH sangat memperhatikan dalam aspek sustainablity dengan menjadikan limbah rumah tangga berupa minyak jelantah menjadi sebuah produk bernilai jual. Aspek sustainable tersebut pula menjadi produk ini Eco-Friendly untuk keperluan sanitasi. Porduk ini selain memiliki daya cleanser serta memiliki nilai estetika dalam hal bentuk, warna, dan aroma yang dapat disesuaikan dengan minat konsumen (custom made). Lalu, produk ini pula turut menekan laju produksi limbah minyak jelantah yang rentan dalam mencemari ekosistem baik daratan maupun perairan. 


\section{Jurnal Pengabdian Kepada Masyarakat BUGUH}

Dipublikasikan

Badan Pelaksana Kuliah Kerja Nyata

Universitas Lampung

Sekretariat Badan Pelaksana Kuliah Kerja Nyata, Universitas Lampung.

Jl. Prof. Dr. Scemantri Brojonegoro No. 1, Bandar Lampung 35145 .

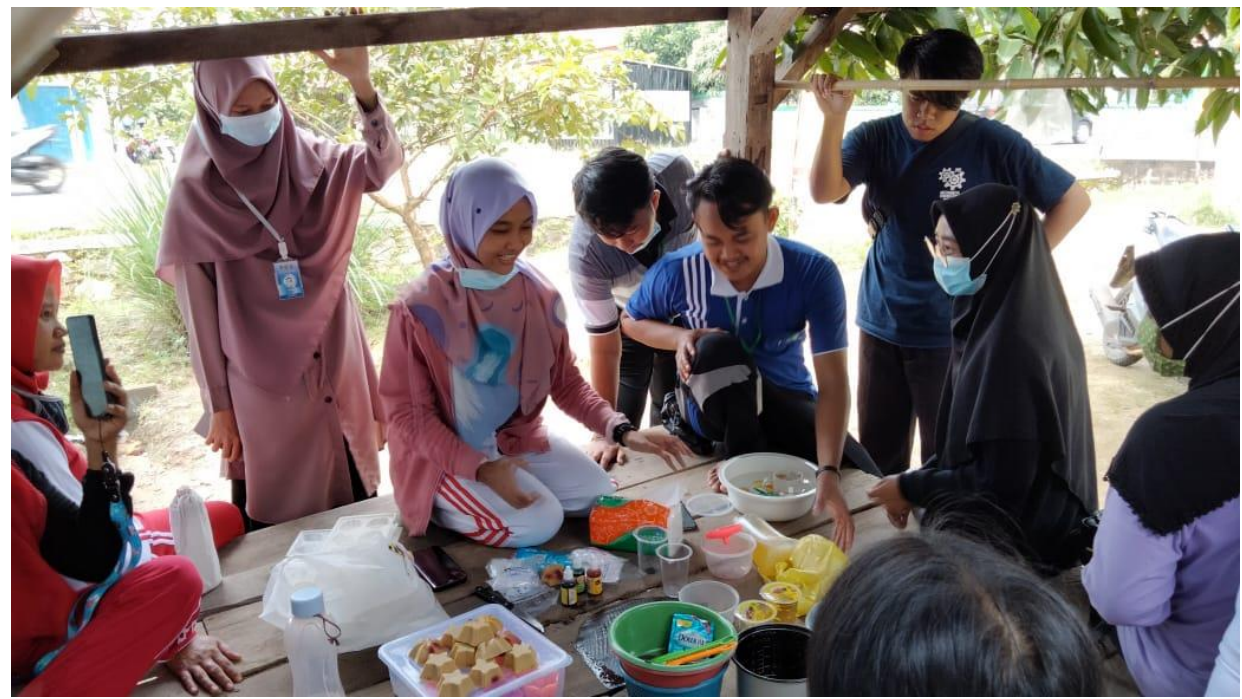

Gambar 1. Proses Pembuatan Sabun Minyak Jelantah

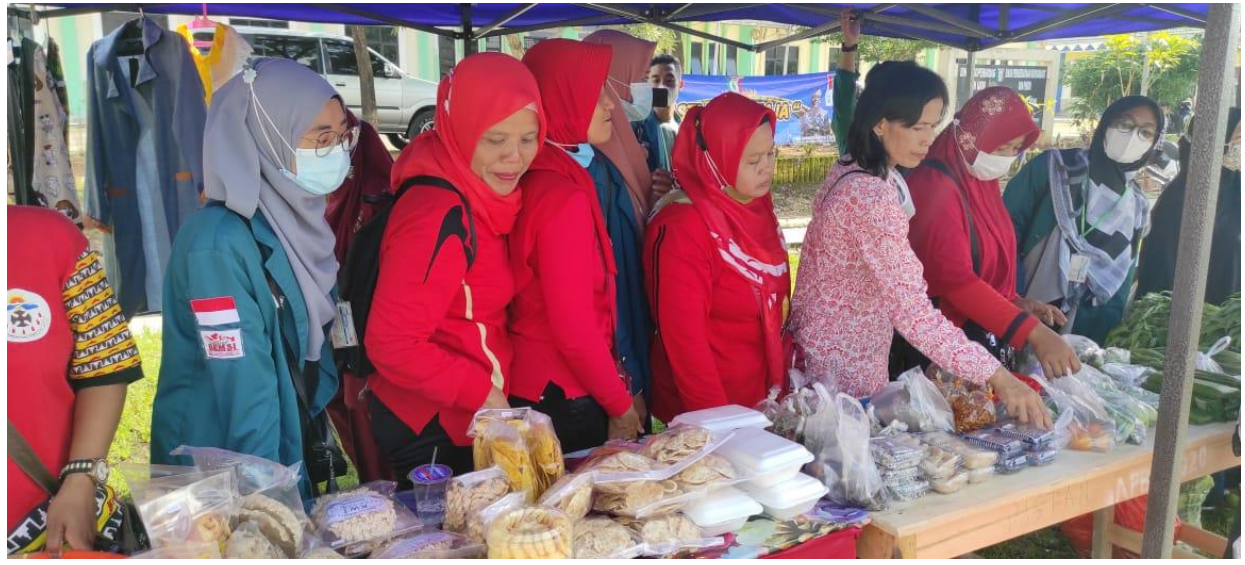

Gambar 2. Memasarkan produk di Pasar Tani Pringsewu

\section{Kesimpulan}

Mengembangkan suatu ide usaha baru dengan membuat suatu produk sanitasi berbahan dasar limbah merupakan suatu usaha yang memiliki peranan yang penting bagi kehidupan masyarakat, hal ini dikarenakan dengan melakukan suatu wujud tersebut secara tidak langsung kita telah berkontribusi untuk menjadi alur dari kehidupan ekosistem serta mendukung Tujuan Pembangunan Berkelanjutan atau Sustainable Development Goals 2030 pada poin ke 12 terkait responsible consumption and production.

Ide produk Buntah yang akan dijual ini berbeda dari olah sabun pada umumnya karena produk ini mempunyai beberapa keunggulan dari produk sabun pada umumnya yakni, ramah lingkungan karena menggunakan bahan-bahan alami sebagai komposisi pelengkap. Memiliki nilai estetika dalam hal bentuk, warna, dan aroma. Kemudian, sabun ini pula merupakan suistainable product yang minim resiko pemakaian. Kami yakin ide usaha ini dapat berkembang serta memiliki nilai jual yang tinggi dan berdaya saing dan akan mencapai keberhasilan serta berkontribusi dalam mewujudkan suatu bentuk pola kehidupan yang berkelanjutan.

\section{Ucapan Terima Kasih}

Terima Kasih kami ucapkan kepada Universitas Lampung, BP-KKN, Masyarakat Desa Gumukmas dan seluruh stakeholder terkait yang telah membimbing dan membantu kami dalam kegiatan pengabdian terjun ke lapangan sehingga kami dapat memberikan sumbangsih manfaat untuk masyarakat. Masyarakat 


\section{BUGUH}

Dipublikasikan

Badan Pelaksana Kuliah Kerja Nyata

Universitas Lampung

Sekretariat Badan Pelaksana Kuliah Kerja Nyata, Universitas Lampung.

Jl. Prof. Dr. Soemantri Brojonegoro No. 1, Bandar Lampung 35145.

perlu diberikan pendampingan lebih lanjut dalam proses mengkomersilkan sabun minyak jelantah sehingga selain untuk mengkampanyekan perilaku berwawasan lingkungan juga dapat meningkatkan perekonomian masyarakat.

\section{Daftar Pustaka}

Haqq, A. A. (2019). Pemanfaatan Limbah Minyak Jelantah Penghasil Sabun Sebagai Stimulus Untuk Meningkatkan Kepedulian Masyarakat Terhadap Lingkungan. Dimasejati: Jurnal Pengabdian Kepada Masyarakat, 1(1). doi:10.24235/dimasejati.v1i1.5410

Prihanto, A., \& Irawan, B. (2018). Pemanfaatan Minyak Goreng Bekas Menjadi Sabun Mandi. Metana, 14(2), 55. doi:10.14710/metana.v14i2.11341

Susanti, M. M., \& Priamsari, M. R. (2019). Pemberdayaan ibu-ibu PKK pengolahan limbah minyak goreng bekas menjadi sabun cair di desa Sidorejo kabupaten Semarang. Indonesian Journal of Community Services, 1(1), 48. doi:10.30659/ijocs.1.1.48-61 